\title{
Measurement of $\mathrm{HbA}_{1 \mathrm{c}}$ and $\mathrm{HbA}_{2}$ by Capillarys 2 Flex Piercing $\mathrm{HbA}_{1 \mathrm{c}}$ programme for simultaneous management of diabetes and screening for thalassemia
}

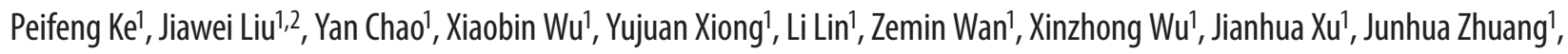 \\ Xianzhang Huang*1 \\ 'Department of Laboratory Science, Second Affiliated Hospital of Guangzhou University of Chinese Medicine, Guangzhou, China \\ 25econd Clinical Medical College, Guangzhou University of Chinese Medicine, Guangzhou, China
}

*Corresponding author: huangxz020@163.com

\begin{abstract}
Introduction: Thalassemia could interfere with some assays for haemoglobin $\mathrm{A}_{1 \mathrm{C}}\left(\mathrm{HbA}_{1 \mathrm{C}}\right)$ measurement, therefore, it is useful to be able to screen for thalassemia while measuring $\mathrm{HbA}_{1 \mathrm{c}}$. We used Capillarys 2 Flex Piercing (Capillarys 2FP) $\mathrm{HbA}_{1 \mathrm{c}}$ programme to simultaneously measure $\mathrm{HbA}_{1 \mathrm{c}}$ and screen for thalassemia.
\end{abstract}

Materials and methods: Samples from 498 normal controls and 175 thalassemia patients were analysed by Capillarys 2FP HbA programme $_{1 c}$ (Sebia, France). For method comparison, $\mathrm{HbA}_{1 \mathrm{c}}$ was quantified by Premier $\mathrm{Hb} 9210$ (Trinity Biotech, Ireland) in 98 thalassaemia patients samples. For verification, $\mathrm{HbA}_{1 \mathrm{C}}$ from eight thalassaemia patients was confirmed by IFCC reference method.

Results: Among 98 thalassaemia samples, Capillarys 2FP did not provide an $\mathrm{HbA}_{1 \mathrm{c}}$ result in three samples with $\mathrm{HbH}$ due to the overlapping of $\mathrm{HbBart}$ 's with $\mathrm{HbA}_{1 \mathrm{C}}$ fraction; for the remaining 95 thalassaemia samples, Bland-Altman plot showed $0.00 \pm 0.35 \%$ absolute bias between two systems, and a significant positive bias above 7\% was observed only in two $\mathrm{HbH}$ samples. The $\mathrm{HbA}_{1 \mathrm{c}}$ values obtained by Capillarys 2FP were consistent with the IFCC targets (relative bias below $\pm 6 \%$ ) in all of the eight samples tested by both methods. For screening samples with alpha (a-) thalassaemia silent/trait or beta ( $\beta$-) thalassemia trait, the optimal $\mathrm{HbA}_{2}$ cut-off values were $\leq 2.2 \%$ and $>2.8 \%$, respectively.

Conclusions: Our results demonstrated the Capillarys $2 \mathrm{FP} \mathrm{HbA}_{1 \mathrm{C}}$ system could report an accurate $\mathrm{HbA}_{1 \mathrm{c}}$ value in thalassemia silent/trait, and $\mathrm{HbA}_{2}$ value ( $\leq 2.2 \%$ for a-thalassaemia silent/trait and $>2.8 \%$ for $\beta$-thalassemia trait) and abnormal bands ( $\mathrm{HbH}$ and/or $\mathrm{HbBart}$ 's for $\mathrm{HbH}$ disease, $\mathrm{HbF}$ for $\beta$-thalassemia) may provide valuable information for screening.

Key words: haemoglobin $A_{1 ;}$; thalassemia; capillary electrophoresis (CE); haemoglobin $A_{2}$

\section{Introduction}

Haemoglobin $A_{1 c}\left(H_{b A_{1 c}}\right)$, the major form of all glycated haemoglobin species, is produced by the non-enzymatic addition of glucose residues to valine moieties at the $\mathrm{N}$-terminal end of the haemoglobin $(\mathrm{Hb}) \beta$-chain (1). $\mathrm{HbA}_{1 \mathrm{c}}$ concentrations are used as an index for long-term glycaemic control, and have recently been recommended for the diagnosis of diabetes mellitus (2-4). Various methods have been developed to measure $\mathrm{HbA}_{1 c^{\prime}}$ however, their accuracy can be adversely affected by the presence of haemoglobinopathies $(5,6)$. In addition, $\mathrm{HbA}_{1 c}$ provides an estimate of blood glucose concentrations over a normal erythrocyte lifespan, and any conditions altering erythrocyte survival (e.g., haemolytic anaemia, iron deficiency anaemia or haemoglobinopathies) may lead to misinterpretation of the $\mathrm{HbA}_{1 \mathrm{c}}$ result and hence misdiagnosis and mistreatment (7).

Thalassemia is the most common monogenetic disease caused by defects in the synthesis of one or more of the haemoglobin chains $(8,9)$. Alpha $(a-)$ thalassemia is caused by reduced or absent synthesis of a globin chains, including four main forms: a-thalassemia silent, a-thalassemia trait (minor), $\mathrm{HbH}$ (intermedia) and $\mathrm{HbBart}$ 's hydrops fetalis syndrome (major). Beta $(\beta-)$ thalassemia is 
caused by reduced or absent synthesis of $\beta$ globin chains, including three main forms: $\beta$-thalassemia trait (minor), $\beta$-thalassemia intermedia and $\beta$-thalassemia major. Several studies have suggested that $\mathrm{HbA}_{1 \mathrm{c}}$ measurement may be affected by thalassemia, which is probably due to different methods used, and the genotypes of samples (1016). In addition, the imbalance of globin chains in thalassemia can lead to haemolysis and impaired erythropoiesis. A decrease of erythrocyte lifespan has been reported in $\beta$-thalassemia (17). Therefore, it is useful to be able to screen for thalassemia while measuring $\mathrm{HbA}_{1 \mathrm{c}}$. Detection of thalassaemia is especially important for the identification of couples at risk of having a child with thalassemia major.

Recently, Sebia (Evry Cedex, France) introduced a capillary electrophoresis (CE) method for the determination of $\mathrm{HbA}_{1 \mathrm{c}}$ using Capillarys 2 Flex Piercing (Capillarys 2FP). Our previous study indicated that $\mathrm{HbA}_{1 \mathrm{c}}$ concentrations measured by Capillarys 2FP system in normal samples, without haemoglobinopathies, showed high correlation and concordance with those obtained using a boronate affinity high-performance liquid chromatography (HPLC) system, i.e. Premier Hb9210 (Trinity Biotech Plc, Bray, Ireland) (5). Further accuracy verification demonstrated a great consistency with International Federation of Clinical Chemistry and Laboratory Medicine (IFCC) reference method (HPLC/ $\mathrm{CE}$ ) values (5). However, the effect of thalassemia on the CE method is unclear. The $\mathrm{HbA}_{1 \mathrm{c}}$ programme on Capillarys 2FP could provide a rapid and reliable separation of $\mathrm{HbA}_{2}$, and $\mathrm{HbA}_{2}$ results are systematically lower compared to those obtained with the haemoglobin programme, with an average bias of $0.29 \%(10)$. $\mathrm{HbA}_{2}$ plays an important role in screening programme for thalassemia: its decrease might reveal $a$-thalassemia while its increase might indicate $\beta$-thalassemia (18). Therefore, in this study, we evaluated the effect of thalassemia on $\mathrm{HbA}_{1 c}$ measurement using Capillarys 2FP by comparison with the Premier Hb9210 and IFCC reference methods, and, furthermore, assessed the $\mathrm{HbA}_{1 \mathrm{c}}$ programme on Capillarys 2FP for thalassemia screening.

\section{Materials and methods}

\section{Subjects}

The Research and Ethics committees of our institution approved this study. All subjects were informed on the study contents and provided written consents for participation. Blood samples were obtained from the Clinical Laboratory of the Second Affiliated Hospital of Guangzhou University of Chinese Medicine between June 2014 and August 2014. These samples included 498 healthy adults (normal controls) and 175 patients with thalassemia. The 175 thalassemia patients included 51 with a-thalassemia silent, 57 with a-thalassemia trait, 7 with $\mathrm{HbH}$ and 60 with $\beta$-thalassemia trait. Whole blood samples were collected in EDTA-containing tubes (2.0 mL, BD Franklin Lakes NJ, USA), divided into small aliquots and stored at $-80^{\circ} \mathrm{C}$ before analysis as previously described $(19,20)$.

Normal control samples were selected from subjects undergoing routine laboratory check-up examinations. Complete blood count (CBC) parameters were measured with BC-6800 (Mindray Medical Electronics Co., Shenzhen, China). Inclusion criteria were as follows: $\mathrm{Hb}$ concentrations $>130 \mathrm{~g} / \mathrm{L}$ (in men) or $>115 \mathrm{~g} / \mathrm{L}$ (in women), mean corpuscular volume $(\mathrm{MCV})>80 \mathrm{fL}, \mathrm{HbF}<5 \%$ without $\mathrm{Hb}$ disorders ( $\mathrm{Hb}$ phenotype analysis was performed by Bio-Rad Variant II system (Bio-Rad, Japan) using the beta thalassemia programme). Thalassemia samples were collected from routine laboratory test samples for thalassemia. Gap-polymerase chain reaction ( $P C R$ ) was used to identify the a-thalassemia deletion mutations, and PCR reverse-blot hybridization was used to detect $\beta$-thalassemia point mutations (YANENG Bioscience Co. Ltd., Shenzhen, China) $(21,22)$.

\section{Method comparison}

The $\mathrm{HbA}_{1 c}$ values of 98 thalassemia patients (29 a-thalassemia silent, 41 a-thalassemia traits, $7 \mathrm{HbH}$ and $21 \beta$-thalassemia traits), were quantified by Capillarys 2FP and Premier Hb9210 systems according to the manufacturers' instructions. The analysers were calibrated once prior to any sample analysis.

Because glycated and non-glycated haemoglobins are separated regardless of haemoglobin species, 
thalassemia is unlikely to interfere with the IFCC reference method and boronate affinity chromatography method (23). The boronate affinity HPLC method Premier Hb9210 was used as the comparative method. For verification, eight thalassemia samples were sent to Shanghai Center for Clinical Laboratory and confirmed by the IFCC reference method HPLC/CE.

\section{Thalassemia screening}

A total of 498 normal controls and 168 thalassemia samples (51 a-thalassemia silent, 57 a-thalassemia traits, and $60 \beta$-thalassemia traits) were analysed by Capillarys $2 \mathrm{FP} \mathrm{HbA}$, programme.

\section{Statistical analysis}

For method comparison, the differences between two methods (Capillarys 2FP vs Premier Hb9210) were presented in a Bland-Altman plot. The relative bias was calculated by the Capillarys 2FP value against the comparative method (Premier Hb9210) value, and $> \pm 7 \%$ was considered clinically significant (National Glycohemoglobin Standardization Programme (NGSP) criterion) (24). For verification testing, the relative bias was calculated by the Capillarys 2FP value against the IFCC reference method value, and the proficiency testing acceptance limit of $\pm 6 \%$ provided by the College of American Pathologists (CAP) was set as the accuracy limit (25).

Measurement data of $\mathrm{HbA}_{2}$ were normally distributed and the independent sample t-test was performed to detect statistical difference between any two groups. Receiver operating characteristic curve (ROC) was applied to determine the best cut-off for screening $\alpha$ - and $\beta$-thalassemia. A P value of $<0.05$ was considered statistically significant. Statistical analysis was performed using the MedCalc version 14.8.1 (MedCalc Software, Ostend, Belgium).

\section{Results}

\section{Method comparison}

Among the 98 thalassaemia samples, $\mathrm{HbA}_{1 c}$ was not detected by Capillarys 2FP in three samples

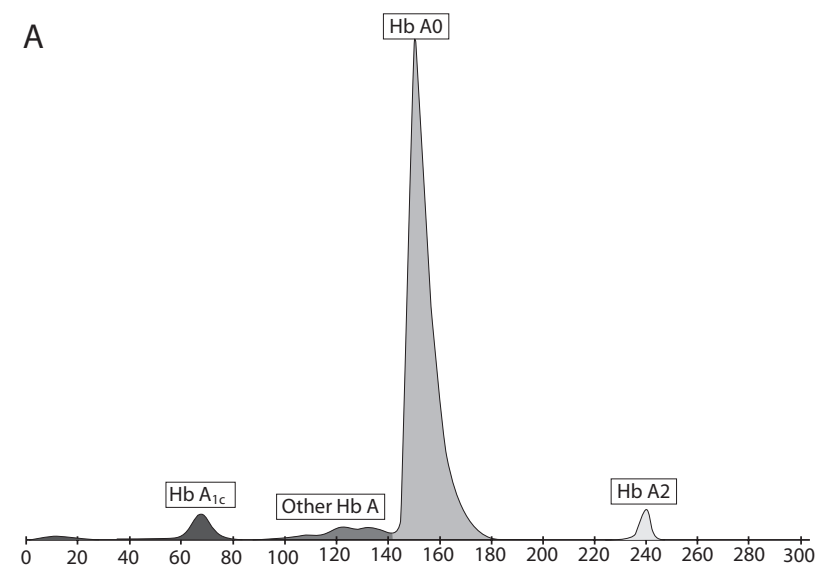

B

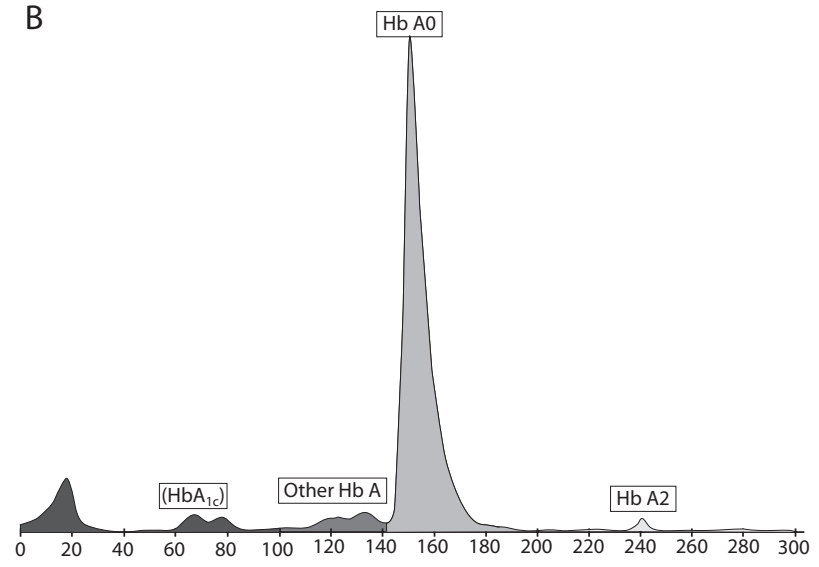

Figure 1. Haemoglobin $A_{1 c}$ analysis by Capillarys 2 Flex Piercing. (A) Normal control. (B) $\mathrm{HbH}$ samples - HbA1c cannot be measured (in parenthesis) due to overlapping with the HbBart's fraction.

with $\mathrm{HbH}$ (Figure 1). For the remaining 95 thalassaemia samples with detectable $\mathrm{HbA}_{1 c^{\prime}}$ the BlandAltman plot showed that the absolute bias of $\mathrm{HbA}_{1 \mathrm{c}}$ was $0.00 \pm 0.35 \%$ between Capillarys 2FP and Premier Hb9210 systems, and 3.4\% of values were discordant (i.e., differences outside the range mean $\pm 2 S D$ ) (Figure 2). A significant positive bias above $7 \%$ was found only in two $\mathrm{HbH}$ samples.

To validate these results, the samples of eight thalassemias including two a-thalassemia silent, two a-thalassemia trait, two $\mathrm{HbH}$ and two $\beta$-thalassemia trait, were analysed by IFCC reference method HPLC/CE for $\mathrm{HbA}_{1 \mathrm{c}}$. The results showed that the $\mathrm{HbA}_{1 \mathrm{c}}$ concentrations obtained by Capillarys 2FP were consistent with the results 


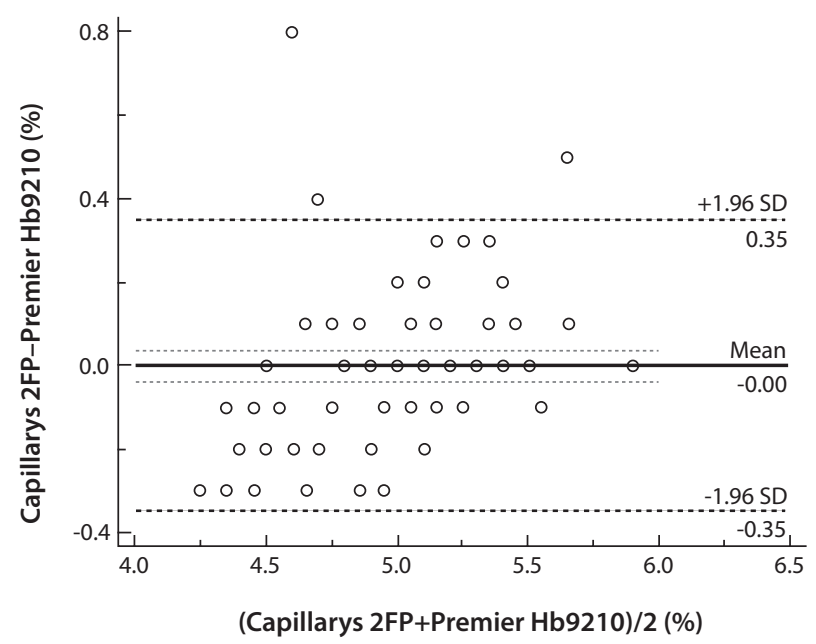

Figure 2. Bland-Altman plot showing the differences in haemoglobin $A_{1 C}$ results between Capillarys 2 Flex Piercing (Capillarys 2FP) and Premier Hb9210 systems in thalassaemia samples (NGSP units, \%). Solid line (mean) - mean difference. Dotted lines - 95\% confidence interval of mean difference. Dashed lines $( \pm 1.96 \mathrm{SD})- \pm 1.96$ standard deviation of mean difference.

obtained by IFCC HPLC/CE reference method, with relative bias below $\pm 6 \%$ (Table 1 ).

\section{Thalassemia screening}

The $\mathrm{HbA}_{2}$ concentration in a-thalassaemia silent/ trait $(0.9-2.6 \%)$ was significantly lower than normal controls $(1.7-2.8 \%)(P<0.001$, Figure $3 A)$. ROC analysis showed an area under curve (AUC) of 0.81 (95\% confidence interval, $0.78-0.84$ ) and the optimal cut-off value was $\leq 2.2 \%$ with a sensitivity of $76.9 \%$ and specificity of $73.7 \%$ (Figure 3B).

The $\mathrm{HbA}_{2}$ concentration in $\beta$-thalassaemia trait (4.0 - 5.6\%) was significantly higher than normal controls $(1.7-2.8 \%)(P<0.001$, Figure $3 A)$. ROC analysis demonstrated an AUC of 1.00 (95\% confidence interval, 0.99 - 1.00) and the optimal cut-off value was $>2.8 \%$ with sensitivity $100 \%$ and specificity $100 \%$ (Figure 3C).

\section{Discussion}

Our results indicate that the presence of $a$-thalassaemia silent/trait and $\beta$-thalassemia trait had no significant effect on the accuracy of $\mathrm{HbA}_{1 \mathrm{c}}$ measurement by Capillarys 2FP. Previous studies have also revealed agreement between Capillarys 2FP and Trinity Biotech Ultra ${ }^{2}$ (boronate affinity chromatography method) or Adams Arkray HA8160 (ion-exchange HPLC method) systems for $\beta$-thalassemia samples $(14,26)$. However, $\mathrm{HbA}_{1 \mathrm{c}}$ concentrations in some $\mathrm{HbH}$ samples became immeasurable as $\mathrm{HbH}$ was separated as the first fraction and the HbBart's fraction overlapped with $\mathrm{HbA}_{1 \mathrm{c}}$. Thus, Capillarys 2FP could provide valuable information ( $\mathrm{HbH}$ and/or HbBart's) for immeasurable samples. For some measurable $\mathrm{HbH}$ samples

TABLE 1. $\mathrm{HbA}_{1 c}$ concentrations obtained by IFCC and Capillarys 2FP

\begin{tabular}{|c|c|c|c|c|c|c|}
\hline & \multirow{2}{*}{ Genotype } & \multicolumn{2}{|c|}{ IFCC reference method } & \multicolumn{2}{|c|}{ Capillarys 2FP } & \multirow{2}{*}{$\begin{array}{c}\text { Relative bias } \\
\text { (\%) }\end{array}$} \\
\hline & & IFCC units, $\mathrm{mmol} / \mathrm{mol}$ & NGSP units, \% & IFCC units, $\mathrm{mmol} / \mathrm{mol}$ & NGSP units, $\%$ & \\
\hline 1 & $-a^{3.7 / a a}$ & 39 & 5.7 & 41 & 5.9 & 3.5 \\
\hline 2 & $-a^{4.2 / a a}$ & 40 & 5.8 & 42 & 6.0 & 3.4 \\
\hline 3 & -_SEA/aa & 30 & 4.9 & 28 & 4.7 & -4.1 \\
\hline 4 & -_SEA/aa & 29 & 4.8 & 29 & 4.8 & 0.0 \\
\hline 5 & $-a^{3.7 /--S E A}$ & 21 & 4.1 & 23 & 4.3 & 4.9 \\
\hline 6 & $-a^{3.7 /--S E A}$ & 31 & 5.0 & 32 & 5.1 & 2.0 \\
\hline 7 & CD41-42 & 31 & 5.0 & 30 & 4.9 & -2.0 \\
\hline 8 & CD41-42 & 38 & 5.6 & 40 & 5.8 & 3.6 \\
\hline
\end{tabular}

$\mathrm{HbA}_{1 c}$ - haemoglobin $\mathrm{A}_{1 \mathrm{c}}$. IFCC - International Federation of Clinical Chemistry and Laboratory Medicine. Capillarys 2FP - Capillarys 2 Flex Piercing. NGSP - National Glycohemoglobin Standardization Programme. The relative bias was calculated in NGSP units, as the Capillarys 2FP value against the IFCC reference method value. The proficiency testing acceptance limit $\pm 6 \%$ of CAP was set as the accuracy limit (25). 

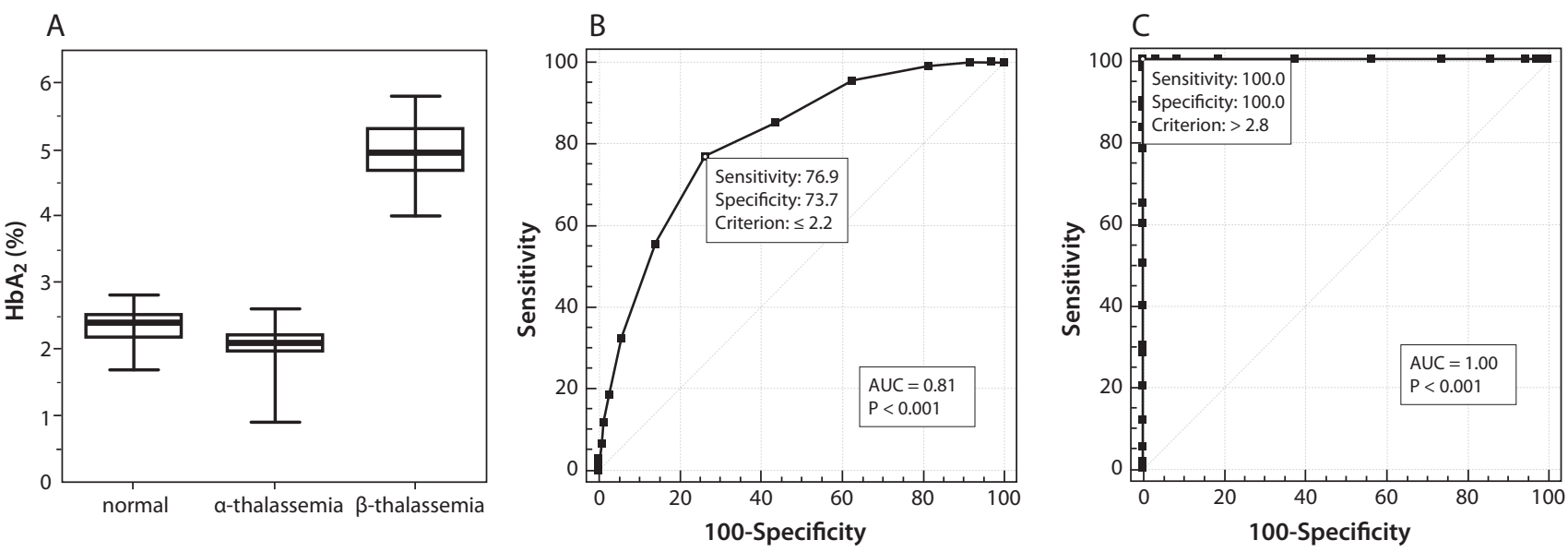

Figure 3. The values of haemoglobin $\mathrm{A}_{2}\left(\mathrm{HbA}_{2}\right)$ were analyzed by Capillarys 2 Flex Piercing for normal controls and thalassaemia. ( $\mathrm{A}$ ) The box-plots show the frequency of $\mathrm{HbA}_{2}$ in normal control, a-thalassaemia silent/trait and $\beta$-thalassaemia trait. The horizontal line in each box represents the median values. The upper and lower limits of each box correspond to the 25th and 75th percentile values. The highest and lowest horizontal bars represent the minimum and maximum values.

(B) For screening a-thalassaemia silent/trait, the receiver operating characteristic curve (ROC) shows an area under curve (AUC) of 0.80 ( $95 \%$ confidence interval, $0.78-0.84$ ) and cutoff value $\leq 2.2 \%$ (sensitivity $76.9 \%$, specificity $73.7 \%$ ).

(C) For screening $\beta$-thalassaemia trait, ROC shows AUC of 1.00 (95\% confidence interval, $0.99-1.00)$ and cutoff value $>2.8 \%$ (sensitivity $100 \%$, specificity $100 \%)$.

by Capillarys 2FP, the results were consistent with that by IFCC reference method.

The limitations of our study are the insufficient number of $\mathrm{HbH}$ samples and IFCC reference method confirmed samples. Another limitation of our study is the lack of $\beta$-thalassemia intermedia/major samples. The $\beta$-thalassemia is characterized by variable increases in $\mathrm{HbF}$ and unusually high $\mathrm{HbA}_{2}$ concentrations. Our previous study found that an increased proportion of $\mathrm{HbF}$ could affect the $\mathrm{HbA}_{1 \mathrm{c}}$ results using Capillarys 2FP (5). Thus, the $\beta$-thalassemia intermedia/major sample with highly elevated $\mathrm{HbF}$ (> 10\%) could interfere the $\mathrm{HbA}_{1 \mathrm{c}}$ measurement by Capillarys 2FP. Capillarys 2FP could report an accurate $\mathrm{HbA}_{1 c}$ value in $\beta$-thalassaemia trait and provide valuable information (elevated $\mathrm{HbA}_{2}$ and/or $\mathrm{HbF}$ ) for $\beta$-thalassemia intermedia/major. Further investigation is warranted using a larger number of thalassemia interme$\mathrm{dia} /$ major patient samples.

$\mathrm{HbA}_{2}$ is well separated and quantified by the $\mathrm{HbA}_{1 \mathrm{c}}$ programme on Capillarys 2FP, while most other $\mathrm{HbA}_{1 c}$ methods are not able to separate $\mathrm{HbA}_{2}$ from $\mathrm{HbA}_{0}$. In the present study, we found the optimal $\mathrm{HbA}_{2}$ cut-off values for screening samples with a-thalassaemia silent/trait or $\beta$-thalassemia trait were $\leq 2.2 \%$ and $>2.8 \%$, respectively, which was consistent with the previous report for $\beta$-thalassemia (10). In addition, abnormal bands could also provide valuable information for thalassemia screening ( $\mathrm{HbH}$ and/or $\mathrm{HbBart}$ 's for $\mathrm{HbH}$ disease, $\mathrm{HbF}$ for $\beta$-thalassemia). The $\mathrm{HbA}_{2}$ concentrations obtained with the $\mathrm{HbA}_{1 \mathrm{c}}$ programme needs to be corrected to obtain the real $\mathrm{HbA}_{2}$ concentrations, which warrants further investigation. Although the $\mathrm{HbA}_{2}$ concentration cannot be reported, laboratories must be cautious when thalassemia is suspected based on screening during $\mathrm{HbA}_{1 \mathrm{c}}$ measurement and communicate with clinicians to note whether the patient is anaemic. Further confirmatory analysis for thalassemia and other indicators to diagnose diabetes are recommended.

In summary, our data, although limited, demonstrated that Capillarys $2 \mathrm{FP} \mathrm{HbA}_{1 c}$ system could report accurate $\mathrm{HbA}_{1 \mathrm{c}}$ results in thalassemia silent/ trait, and $\mathrm{HbA}_{2}$ concentrations $(\leq 2.2 \%$ for a-thalassaemia silent/trait and $>2.8 \%$ for $\beta$-thalassemia trait) and abnormal bands $(\mathrm{HbH}$ and/or HbBart's for $\mathrm{HbH}$ disease, $\mathrm{HbF}$ for 
$\beta$-thalassemia) may provide valuable information for screening.

\section{Acknowledgments}

This research was supported by grants from the $\mathrm{Na}-$ tional Natural Science Foundation of China (81572088), the Natural Science Foundation of Guangdong Province (2015A030313340), the Foundation of Guangdong Provincial Hospital of Chinese Medicine (2014KT1593), the National Key Technolo-

\section{References}

1. Peterson KP, Pavlovich JG, Goldstein D, Little R, England J, Peterson CM. What is hemoglobin A1c? An analysis of glycated hemoglobins by electrospray ionization mass spectrometry. Clin Chem 1998;44:1951-8.

2. World Health Organization (WHO). Use of glycated haemoglobin (HbA1c) in the diagnosis of diabetes mellitus. Abbreviated Report of a WHO Consultation. Geneva, Switzerland. WHO Press, 2011.

3. Gillett MJ. International Expert Committee report on the role of the A1c assay in the diagnosis of diabetes. Diabetes Care 2009;32:1327-34. https://doi.org/10.2337/dc09-9033

4. Sacks DB, Arnold M, Bakris GL, Bruns DE, Horvath AR, Kirkman MS, et al. National Academy of Clinical Biochemistry; Evidence-Based Laboratory Medicine Committee of the American Association for Clinical Chemistry. Guidelines and recommendations for laboratory analysis in the diagnosis and management of diabetes mellitus. Diabetes Care 2011;34:e61-99. https://doi.org/10.2337/dc11-9998

5. Wu X, Chao Y, Wan Z, Wang Y, Ma Y, Ke P, et al. A comparative evaluation of the analytical performances of Capillarys 2 Flex Piercing, Tosoh HLC-723 G8, Premier Hb9210, and Roche Cobas 1501 Tina-quant Gen 2 Analyzers for HbA1c determination. Biochem Med (Zagreb) 2016;26:353-64. https:// doi.org/10.11613/BM.2016.039

6. Zhang XM, Wen DM, Xu SN, Suo MH, Chen YQ. Effects of hemoglobin variants $\mathrm{HbJ}$ Bangkok, $\mathrm{HbE}, \mathrm{HbG}$ Taipei, and $\mathrm{HbH}$ on analysis of glycated hemoglobin via ion-exchange highperformance liquid chromatography. J Clin Lab Anal 2017 April 13 [cited 2017 may 5]. doi: https://doi.org/10.1002/ jcla.22214 [Epub ahead of print]

7. Coban E, Ozdogan M, Timuragaoglu A. Effect of iron deficiency anemia on the levels of hemoglobin A1c in nondiabetic patients. Acta Haematol 2004;112:126-8. https://doi. org/10.1159/000079722

8. Galanello R, Origa R. Beta-thalassemia. Orphanet J Rare Dis 2010;5:11. https://doi.org/10.1186/1750-1172-5-11

9. Weatherall DJ, Clegg JB. Inherited haemoglobin disorders: an increasing global health problem. Bull World Health Organ 2001;79:704-12. gies R\&D Program of China (2012BAI37B01), the National Special R\&D Program of Major New Drugs of China (2012ZX09303009-003), the State Administration of Traditional Chinese Medicine, P. R. China (201007005), and the National Science \& Technology Pillar Program during the Twelfth Five-year Plan Period (2013BAI02B04).

\section{Potential conflict of interest}

None declared.
10. Urrechaga E. High-resolution $H b A(1 c)$ separation and hemoglobinopathy detection with capillary electrophoresis. Am J Clin Pathol 2012;138:448-56. https://doi.org/10.1309/ AJCPVYW9QZ9EVFXI

11. Lee SC, Wang LH, Tsai SM, Fang HY, Tsai LY. Effects of the $\mathrm{Hb} \mathrm{E}, \mathrm{Hb} \mathrm{H}$ and $\mathrm{Hb}$ G-Taichung variants on $\mathrm{HbAlc}$ values by the Bio-Rad variant II turbo analyzer. Clin Biochem 2011;44:1338-42. https://doi.org/10.1016/j.clinbiochem.2011.08.907

12. Agilli M, Yaman H, Aydinl FN. Hb H Interference on Measurement Of HbA1c With lon-Exchange HPLC. Acta Inform Med 2013;21:216-8. https://doi.org/10.5455/aim.2013.21.216218

13. Pravatmuang $P$, Sae-Ngow $B$, Whanpuch $T$, Leowattana W. Effect of $\mathrm{HbE}$ and $\mathrm{HbH}$ on $\mathrm{HbA} 1 \mathrm{C}$ level by ionic exchange HPLC comparing to immunoturbidimetry. Clin Chim Acta 2001;313:171-8. https://doi.org/10.1016/S00098981(01)00670-2

14. Ji L, Yu J, Zhou Y, Xia Y, Xu A, Li W, et al. Erroneous HbA1C measurements in the presence of $\beta$-thalassemia and common Chinese hemoglobin variants. Clin Chem Lab Med 2015;53:1451-8. https://doi.org/10.1515/cclm-2014-0598

15. Al-Fadhli SM, Ahmad AA, Al-Jafar HA. Effect of sickle cell trait and $B$-Thalassemia minor on determinations of $\mathrm{HbA} 1 \mathrm{c}$ by an immunoassay method. Saudi Med J 2001;22:686-9.

16. Polage C, Little RR, Rohlfing CL, Cole TG, Roberts WL. Effects of beta thalassemia minor on results of six glycated hemoglobin methods. Clin Chim Acta 2004;350:123-8. https://doi. org/10.1016/j.cccn.2004.07.015

17. Gallo E, Pich P, Ricco G, Saglio G, Camaschella C, Mazza U. The relationship between anemia, fecal stercobilinogen, erythrocyte survival, and globin synthesis in heterozygotes for beta-thalassemia. Blood 1975;46:693-8.

18. Mosca A, Paleari R, Ivaldi G, Galanello R, Giordano PC. The role of haemoglobin A2 testing in the diagnosis of thalassaemias and related haemoglobinopathies. J Clin Pathol 2009;62:13-7. https://doi.org/10.1136/jcp.2008.056945

19. Simon $M$, Hoover JD. Effect of sample instability on glycohemoglobin (HbA1) measured by cation-exchange chromatography. Clin Chem 1982;28:195-8. 
20. John WG, Little R, Sacks DB, Weykamp C, Lenters-Westra $E$, Hornsby $T$, et al. Multicentre evaluation of the Premier Hb9210 HbA1c analyser. Clin Chem Lab Med 2015;53:31927. https://doi.org/10.1515/cclm-2014-0589

21. Lin $M$, Wang $Q$, Zheng $L$, Huang $Y$, Lin F, Lin $C P$, et al. Prevalence and molecular characterization of abnormal hemoglobin in eastern Guangdong of southern China. Clin Genet 2012;81:165-71. https://doi.org/10.1111/j.13990004.2011.01627.x

22. Cai SP, Wall J, Kan YW, Chehab FF. Reverse dot blot probes for the screening of beta- thalassemia mutations in Asians and American blacks. Hum Mutat 1994;3:59-63. https://doi. org/10.1002/humu.1380030110

23. Jeppsson JO, Kobold U, Barr J, Finke A, Hoelzel W, Hoshino T, et al. Approved IFCC reference method for the measurement of HbA1c in human blood. Clin Chem Lab Med 2002;40:7889. https://doi.org/10.1515/CCLM.2002.016
24. National Glycohemoglobin Standardization Programme (NGSP). HbA1c methods: Effects of Hemoglobin Variants ( $\mathrm{HbC}, \mathrm{HbS}, \mathrm{HbE}$ and $\mathrm{HbD}$ traits) and Elevated Fetal Hemoglobin (HbF). Available at: http://www.ngsp.org/interf.asp. Accessed April 22nd 2017.

25. National Glycohemoglobin Standardization Programme (NGSP). College of American Pathologists (CAP) Survey Data. Available at: http://www.ngsp.org/CAPdata.asp. Accessed April 22nd 2017.

26. Marinova M, Altinier S, Caldini A, Passerini G, Pizzagalli $G$, Brogi $M$, et al. Multicenter evaluation of hemoglobin A1c assay on capillary electrophoresis. Clin Chim Acta 2013;424:207-11. https://doi.org/10.1016/j.cca.2013.06.014 